\title{
Erratum to: The effect of visual spatial attention on audiovisual speech perception in adults with Asperger syndrome
}

\author{
Satu Saalasti $\cdot$ Kaisa Tiippana $\cdot$ Jari Kätsyri • \\ Mikko Sams
}

Published online: 15 February 2012

(C) Springer-Verlag 2012

Erratum to: Exp Brain Res (2011) 213:283-290

DOI 10.1007/s00221-011-2751-7

In the original publication of this article, the authors would like to correct an error overlooked prior to publication:

The second affiliation of the co-author, Jari Kätsyri, should be the "Aalto University School of Economics" (and not the School of Science).

The online version of the original article can be found under doi:10.1007/s00221-011-2751-7.

S. Saalasti $(\bowtie) \cdot$ K. Tiippana Institute of Behavioural Sciences, University of Helsinki, P.O. Box 9, 00014 Helsinki, Finland

e-mail: satu.saalasti@helsinki.fi

S. Saalasti

Department of Pediatric and Adolescent Medicine,

Helsinki University Central Hospital, Helsinki, Finland

J. Kätsyri · M. Sams

Mind and Brain Laboratory, Department of Biomedical Engineering and Computational Science (BECS), Aalto University School of Science, Helsinki, Finland

J. Kätsyri

Knowledge Media Laboratory, Center for Knowledge and Innovation Research (CKIR), Aalto University School of Economics, Helsinki, Finland 